Original scientific paper

UDK: $327(5 / 9)$

DOI: $10.5937 / J R S 1901039 \mathrm{~T}$

Received: 28 March 2019 / Accepted: 21 May 2019

\title{
Maps in International Security: Revealing the Unseeable
}

\author{
SEAD TURČALO* \\ University of Sarajevo, Faculty of Political Sciences, Bosnia and Herzegovina
}

As already noted in the Introduction to this Special Issue, several databases offer vast amounts of information on conflict, wars, political violence, that are unseeable and incomprehensible to a wider audience before being selected, analysed, and communicated in an accessible and intelligible way. But several authors have questioned the objectivity of maps and the scientificity of the messages they convey. ${ }^{1}$ For, as argued by Harley, it is through this process of selection and analysis that mapsbecame more a reproduction of power relations than an objective display of textual and numerical information. ${ }^{2}$ Similarly, as Dodge and Kitchin point out, mapping is concerned more with creating than revealing knowledge - which means that maps are constructions intended to draw particular impressions, instead of being impartial reflections of processes, relations, and correlations between the phenomena and factors emerging in different parts of the world. ${ }^{3}$

In this special issue of Journal of Regional Security, spatialised text and data on peace and security-related issues are presented by authors who, by mapping textual and numerical descriptions and offering explanations of them, demonstrate that a meaningful understanding of maps requires viewing them as a link in a chain of intertextual relations with the data used to create them. Seven contributions, by a variety of scholars, reflect the spatial turn that has been revived in security studies througha revolution of neo-geography that has completely changed and, to a large extent democratised, the cartographic representation of spaces and places having to do with international security. ${ }^{4}$ Although many of the tools that sparked this revolution have existed since the 1960s (e.g., the Canada Geographic Information System), their accessibility in recent years to individuals and non-expert communities has enabled them to represent space in previously unknown ways.

1 Harley 1989, Wood 1992; Dodge and Kitichin 2001; Pickles 2006.

2 Harley 1989.

3 Dodge and Kitchin 2001, 3.

4. Dror et al. 2015.

*sead.turcalo@fpn.unsa.ba 
This neo-geographic revolution, which has impacted mapping in the field of security, has been called 'counter-mapping'or 'mapping against power. ${ }^{5}$ Counter-mapping is considered "any effort that fundamentally questions the assumptions or biases of cartographic conventions, that challenges predominant power effects of mapping, or that engages in mapping in ways that upset power relations." ${ }^{6}$ Still, while counter-mapping is regarded as a means of challenging the power relations and imbalances inscribed in maps through the exclusion and inclusion of certain information, Wood argues that it is aimed at competing in a struggle of geographical imaginations, not at being politically progressive. ${ }^{7}$

Some contributions to this Special Issue involve the reading of maps as a counterpoint to dominant narratives on the risk of domestic terrorism. For instance, Nemeth and Masulein show in their map of the average annual risk of domestic terrorism that the spatial distribution of this phenomenon does not confirm the prevailing discourse. When set in context, their map indicates that a heightened risk of terrorism exists in areas that have already been exposed to other kinds of violence, or in border countries that have experienced it as spill-over.

This finding was corroborated in a recent study by Marinen et al., ${ }^{8}$ which found that terrorist attacks are most likely to occur in places that feature various sets of grievances or "recent civil violence."Agheyi seasserts further that the risk of terrorism is increased by spatial injustices (uneven development, resource scarcity, etc.) within a country or region. ${ }^{9}$ Mapping the data of terrorism, as Nemeth and Muselein have done, contributes to the ongoing trend of reversing an ageographic approach to terrorism research. According to Mustafa, this can add not only to "unpacking discursive constructs" but also to the development of improved responses to terrorism. ${ }^{10}$

Maps presented in this Special Issue visualise data on conflict, terrorism, and other forms of violence on one hand, while revealing concealed aspects of the knowledge that have been created through these data or imagery, on the other. As Olbrich's contribution shows, for example, remote sensing is useful to collecting sensitive information on an isolated country such as North Korea from a secure distance, which can be distributed at discounted cost to non-governmental actors. Yet, while this may sound like an opportunity for a nearly limitless democratisation of mapping even of security-related information; as a form of geo-surveillance, maps remain in the realm of corporate and state-controlled expressions of "geo-power." ${ }^{11}$ Indeed, Olbrich reveals how it is precisely

5 Hodgson and Schroeder 2002, 81.

6 Harris and Hazen, 115 in Dalton and Deese 2012, 442.

7 Dalton and Deese 2012, 443.

8 Marinen et al. 2018.

9 Agheyise 2016.

10 Mustafa 2005, 2.

11 O'Tuathail 1996, 5. 
the democratisation of mapping itself that could be instrumentalised by gatekeepers who determine what imagery is publicly accessible, and which of it is offeredat a discount. Making only low-resolution imagery of North Korea accessible and/or affordable to nongovernmental actors partially reflects the national security interests of the US, for instance, and means that maps using this imagery are (re)producing the geostrategic thinking and priorities of a particular country. This reduces all the contemporary issues surrounding North Korea to the traditional security dimension, in neglect of human security issues faced by North Korean citizens.

This restriction of access to high-resolution imagery and certain geospatial data and information is determined by the US Government as a function of three criteria: usefulness, uniqueness, and benefits and costs. ${ }^{12}$ The question of usefulness addresses whether the data and information at issue could be exploited by terrorists, while uniqueness tests whether it could be acquired from any other sources. The last criterion, benefits and costs, weighs the benefits of any given data to the general public against the costs or risk of it being misused by terrorists. If the criteria of usefulness or/and uniqueness are met, the data or information in question are removed from the map, controlled, or withheld from release to the public. The content of maps can thus be discerned only if the forces at play around mapping are well understood.

One unique form of mastering space relates to the phenomenon of roadblocks in the Central African Republic (CAR). As presented in a map by Schouten and Jaillon, the usage of roadblocks by different actors in CAR is a way of spatialising their sovereign claims in certain areas, which have been reinforced through the creation of a place-specific economy in CAR linked to the droit de fouille, "understood as an entitlement to freedom from search." ${ }^{3}$ As Lombard elaborates in her article, "Navigational Tools for Central African Blocks," the amount that a truck operator or goods owner must pay at roadblocks to remain free from search depends not only on their relationship with the roadblocker, but also on the mood of thatroadblocker. ${ }^{14}$

That mood and emotion play a role not only in the decisions of roadblockers in CAR about what sum to demand from traders and transporters to ensure their droit de fouille, but could also be used to test correlations related to a nation's attitude towards conflict, is presented in the contribution by Bobić and Kantorowitz on anthems and interstate wars. Mapping the sentiments displayed in the texts of national anthems and comparing them with data from the Militarized Interstate Disputes Dataset, these authors have, even with all the limitations they acknowledge in their research, introduced a significant element

12 Medina and Hepner 2013, 450.

13 In Central Africa the term droit de fouille (the right of search) has multiple meanings. Droit is not only used in its meaning of "right" but also to describe tax and entitlement, so that in context of roadblockers in CAR droit de fouille is often applied as the "entitlement to freedom of search“. Lombard 2013, 162.

$14 \quad$ Ibid., 163. 
that is often neglected in analyses of wars and conflict in International Relations. Indeed, when reflecting on his seminal work Perception and Misperception in International Politics, Robert Jervis recognised as a shortcoming of the book the fact that the emotional dimension of international politics had been "completely put aside."15

Considering that emotions go beyond individual feelings and are a part of cultural constructs that affect collectives, national anthems can be seen as a response to the challenges a nation has encountered through its history. As argued by Ahmed, negative sentiments (fear or hate) are not simply responses "to some existential danger that this person or object possess, but to the cultural memories or shared social norms that have marked them as dangerous in our minds." ${ }^{16}$ As a matter of security, these sentiments affect political and social engagement and impact civic identity.

In this vein, Mayer and Hammerschimidt mapped the spatial-temporal dimension of electoral violence, which they define as "a sub-category of political violence, which occurs during the election period with the objective to influence the electoral process and by extension the election outcome."17 By mapping and clustering episodes of violence in the 180 days prior to the 2005 parliamentary elections in Afghanistan, they proved that an increase in diverse violent incidents occurred in the lead-up to the elections, particularly in areas controlled by non-state actors. The reason for this rise in violence in that period can be found in the research of Berrebi and Klor, who found that violence has a stronger impact when it occurs closer to an election. ${ }^{18}$

Importantly, this Special Issue demonstrates that maps represent extremely potent modes of communication, ${ }^{19}$ because they provide an understandable way of explaining the complexity of the world, especially in areas we are unable to grasp in textual or numerical descriptions. Yet it additionally highlights that, through the classification and selection of the information being mapped, representations of the world or certain parts of it are created, and these representations have an impact on diverse aspects of our lives. This includes our perceptions of various security or securitised issues, such as the possible effects of migrant flows on respective countries, whether we see a potential for conflict in our communities, or whether we feel endangered by terrorism. As such, in the areas of peace and security studies, maps not only visualise stored data but serve as a powerful analytical tool that adds to our understanding of different security phenomena.

15 Crawford 2015, xvii.

16 Cited in Gregory and Ahall 2015, 4.

17 Hoglund in Newman 2013, 11.

18 Berrebi and Klor 2007 in Newman 2013, 14.

19 Dodge and Kitchin 2001, 2-3. 


\section{References}

Agheyisi, Justin E. 2016. “Terrorized places and spaces: the geographical dimension of African terrorism." African Geographical Review 36(3): 305-319. doi:10.1080/193 76812.2016.1253487

Ahall, Linda, and Thomas Gregory. 2015. Emotions, Politics and War. New York: Routledge.

Berrebi, Claude, and Esteban F. Klor. 2007. "Are Voters Sensitive to Terrorism?

Direct Evidence from the Israeli Electorate."SSRN Electronic Journal. doi:10.2139/ ssrn. 963965

Boria, Edoardo. 2008. "Geopolitical Maps: A Sketch History of a Neglected Trend in Cartography.” Geopolitics 13(2): 278-308. doi:10.1080/14650040801991522

Crawford, Neta. 2015. Preface. In Emotions, Politics and War, edited by Linda Ahall, and Thomas Gregory, xvi-1. New York: Routledge.

Demko, George J., and William B. Wood. 2018. Reordering the World. Boulder: Routledge.

Dodge, Martin, and Rob Kitchin. 2001. Atlas of Cyberspace. Harlow: AddisonWesley.

Dror, T., S. Dalyot, and Y. Doytsher. 2015. "Quantitative evaluation of volunteered geographic information paradigms: social location-based services case study."Survey Review 47(344): 349-362. doi:10.1179/1752270615y.0000000013.

Harley, J B. 1989. "Deconstructing the map". Cartographica: The International Journal for Geographic Information and Geovisualization 26(2): 1-20. doi:10.3138/ e635-7827-1757-9t53

Höglund, Kristine. 2009. "Electoral Violence in Conflict-Ridden Societies: Concepts, Causes, and Consequences." Terrorism and Political Violence 21 (3): 412-427. doi:10.1080/09546550902950290.

Lombard, Louisa. 2013. "Navigational Tools for Central African Roadblocks." PoLAR: Political and Legal Anthropology Review 36(1): 157-173. doi:10.1111/plar.12008.

Marineau, Josiah, Henry Pascoe, Alex Braithwaite, Michael Findley, and Joseph Young. 2018. "The local geography of transnational terrorism." Conflict Management and Peace Science. doi:10.1177/0738894218789356 
Medina, Richard M., and George F. Hepner. 2013. The Geography of International Terrorism. Boca Raton: Taylor \& Francis.

Mustafa, Daanish. 2005. "The Terrible Geographicalness of Terrorism: Reflections of a Hazards Geographer." Antipode 37(1): 72-92. doi:10.1111/j.0066-4812.2005.00474.x

Newman, Lindsay Shorr. 2013. "Do Terrorist Attacks Increase Closer to Elections?" Terrorism and Political Violence 25 (1): 8-28. doi:10.1080/09546553.2013.733247.

O’Tuathail, Gearoid. 1996. Critical Geopolitics. Milton: Taylor \& Francis.

Pickles, John. 2006. A History of Spaces. London: Routledge.

Wood, Denis. 1992. The Power of Maps. New York: Guilford. 